\title{
The transition from resident to consultant
}

\section{Kim W. M. van Delft ${ }^{1}$ (D) $\cdot$ Gemma Nightingale ${ }^{2}$}

Received: 10 May 2019 / Accepted: 28 May 2019 / Published online: 13 June 2019

(C) The International Urogynecological Association 2019

The transition from resident to a new consultant is a remarkable change for the doctor concerned. The purpose of (sub)specialty training is to prepare the trainee for the new post. The main focus of (sub)specialty training is to gain knowledge and expertise regarding the medical content, investigations, treatment options, and surgical skills. Management and leadership courses are increasingly incorporated into training to supplement the soft skills learnt during residency, but is this enough?

To start, it is important to understand that transition is not a single moment, but a continuum [1]. Large changes require coping strategies to allow us to face new challenges and opportunities while being able to deal with the stress and emotions that accompany them $[2,3]$. This is not commonly addressed during training.

Making the jump from resident to consultant can be likened to obtaining your driving license. Everybody is aware that after obtaining "the piece of paper" you are not an experienced driver, which requires time behind the wheel and exposure to roads. Similarly, the completion of training and obtaining "competence" does not give the breadth of knowledge that experience does. Literature reveals that the training of young drivers could best be focused on the translation of learning to independent driving [4]. Therefore, one should not only focus on the technical skills of driving a car, but teaching safe attitudes and norms, judgment, and self-control at the wheel [4].

A parallel can also be drawn with the military. The Army defines readiness as "the capability of its forces to conduct the

Kim W. M. van Delft

kim.vandelft@radboudumc.nl

Gemma Nightingale

gemmanightingale@nhs.net

1 Obstetrics and Gynaecology, Radboud University Medical Centre, Geert Grooteplein Zuid 10 (route 791), Postbox 9101, 6500 HB Nijmegen, The Netherlands

2 ST7 Obstetrics and Gynaecology, Basingstoke and North Hampshire Hospital, Basingstoke, UK full range of military operations... readiness is a function of how well units are manned, equipped, trained, and led" [5]. Soldiers' training is aimed at getting them "fit to fight" and in the best physical shape they can achieve. Resilience, endurance, strength, and hand-eye coordination are optimized during training and this creates self-confidence for the individual. This could be extrapolated to medical training; to get "ready for consultancy" you need to spend years learning, practicing, adapting, and honing clinical and surgical skills. However, unlike medical training, the military also focuses on mental preparedness for accepting and controlling one's fear, because no amount of training can fully prepare a soldier for all eventualities of war.

A recent survey among 147 Dutch gynecologists who had finished their general obstetrics and gynecology residency within the past $1-5$ years revealed that the majority $(80 \%$, $n=113$ ) of new consultants were well prepared for their post [6]. The $20 \%$ of gynecologists who feel less prepared hamper knowledge about (hospital) management, supervision experience, and sufficient surgical experience [6].

Besides the clinical and surgical skills required to become a consultant urogynecologist, there are a plethora of additional skills that one is suddenly expected to excel at. Whilst juggling your own referrals and theatre schedules, responding to complaints, and preparing business cases, you also have to manage and train junior doctors. To a large extent, trainees are protected from these additional responsibilities during residency. Nonmedical tasks and the delegation of responsibilities are the biggest issues for new consultants [3]. Important components to prepare for transition are experience with decision-making, responsibility, and the ability to prioritize and to cope with stress [7, 8]. Furthermore, burnout among new consultants correlates with lack of preparation in generic competencies, supervision during on-call shifts, (time) management, financial acumen, and (multidisciplinary) collaboration [9].

Yardley et al. have clearly described the most important positive effects on transition in their review paper [1]:

- Appropriate work-based learning

- Appropriate independence and responsibility 
- Learning to manage uncertainty

- Fostering active decision-making and resiliency

- Supportive coaching and mentoring

From a practical point of view, improvement in training can be achieved by introducing management and leadership tasks during residency, in addition to more responsibility with supervision of juniors [7]. The emphasis is on personal coping strategies as these are thought to help the development of supervision skills [10]. Second, programs to familiarize new consultants with organizational structure and the culture of their new workplace would be helpful [7], including getting to know the department and its residents [10]. The third suggestion is sharing experiences within peer groups [7].

The positive effect of progressive independence during training has been shown in a comparative survey among newly appointed Danish and Dutch consultants. The program in Denmark has more progressive independence for residents and reduced working hours. Danish consultants were much better prepared for their new role, especially their generic competencies. As a result, Danish consultants experience the transition from resident to consultant with much less stress, resulting in lower burn-out ratios [11].

Last, when working in a supervisory capacity, it is very helpful to conduct proactive, problem-oriented behavior. An example of this is to seek feedback on your performance and to discuss (critical) incidents with residents [10]. On the other hand, emotion-oriented behavior, such as seeking comfort and support from colleagues and friends, is a more evasive method [10]. Although this may sometimes be important, it primarily provides temporary alleviation of negative emotions and does not lead to behavioral change [10].

\section{Conclusion}

The transition from a resident to a consultant should not be seen as a moment in time, but as ongoing. This period of transition provides opportunities for personal and professional development, for which support is needed.

Some practical tips to aid a smooth transition include:

- Early exposure to a supervising role during residency

- Extensive induction program for new consultants to become familiar with the department, colleagues, and culture
- Social support by other consultants, for example, peer support and mentoring

- To aim for proactive problem-oriented behavior

\section{Compliance with ethical standards}

Conflicts of interest None.

\section{References}

1. Yardley S, Westerman M, Bartlett M, Walton JM, Smith J, Peile E. The do's, don't and don't knows of supporting transition to more independent practice. Perspect Med Educ. 2018;7:8-22.

2. Brown J, Ryland I, Shaw N, Graham D. Working as a newly appointed consultant: a study into the transition from specialist registrar. Br J Hosp Med (Lond). 2009;70:410-4.

3. Teunissen PW, Westerman M. Opportunity or threat: the ambiguity of the consequences of transitions in medical education. Med Educ. 2011:45:51-9.

4. Simons-Morton B, Ehsani JP. Learning to drive safely: reasonable expectations and future directions for the learner period. Safety (Basel). 2016;2(4):20. https://doi.org/10.3390/safety2040020.

5. Feickert A. The Army's sustainable readiness model (SRM). 2017. Available at https://fas.org/sgp/crs/natsec/IN10679.pdf.

6. Louwers YV, Janse JA, Romijn LM, Hofman LN, van der Post JAM. Pre- en periregistratieperikelen van de jonge gynaecoloog. Ned Tijdschr Obstet Gynaecol. 2018;131:95-7 [Dutch].

7. Westerman M, Teunissen PW, van der Vleuten CP, Scherpbier AJ, Siegert CE, van der Lee N, et al. Understanding the transition from resident to attending physician: a transdisciplinary, qualitative study. Acad Med. 2010;85:1914-9.

8. Tallentire VR, Smith SE, Skinner J, Cameron HS. Understanding the behaviour of newly qualified doctors in acute care contexts. Med Educ. 2011;45:995-1005.

9. Westerman M, Teunissen PW, Fokkema JP, van der Vleuten CP, Scherpbier AJ, Siegert CE, et al. The transition to hospital consultant and the influence of preparedness, social support, and perception: a structural equation modelling approach. Med Teach. 2013;35:320-7.

10. Westerman M, Teunissen PW, Fokkema JP, Siegert CE, van der Vleuten CP, Scherpbier AJ, et al. New consultants mastering the role of on-call supervisor: a longitudinal qualitative study. Med Educ. 2013;47:408-16.

11. Westerman M, Teunissen PW, Jørgensen RL, Fokkema JP, Siegert $\mathrm{CE}$, Van der Vleuten CP, et al. The transition to hospital consultant: Denmark and the Netherlands compared on preparedness for practice, perceived intensity and contextual factors. Med Teach. 2013;35:481-9.

Publisher's note Springer Nature remains neutral with regard to jurisdictional claims in published maps and institutional affiliations. 